\title{
The possible effects on socio-economic inequalities of introducing HPV testing as primary test in cervical cancer screening programs
}

\author{
Paolo Giorgi Rossi ${ }^{1}{ }^{*}$, Flavia Baldacchini ${ }^{1}$ and Guglielmo Ronco ${ }^{2}$ \\ ' Servizio Interaziendale di Epidemiologia, Azienda Unità Sanitaria Locale di Reggio Emilia, Reggio Emilia, Italy \\ 2 Unit of Cancer Epidemiology II, Center for Cancer Epidemiology and Prevention (CPO), Turin, Italy
}

Edited by:

Silvia De Sanjose, Catalan Institute of

Oncology, Spain

Reviewed by:

Elisabeth Couto, Norwegian

Knowledge Centre for the Health

Services, Norway

Maria Paula Curado, International

Prevention Research Institute, France

\section{*Correspondence:}

Paolo Giorgi Rossi, Servizio

Interaziendale di Epidemiologia,

Azienda Unità Sanitaria Locale di

Reggio Emilia, via Amendola 2,

Reggio Emilia 42122, Italy

e-mail: paolo.giorgirossi@ausl.re.it
Background: Screening with HPV is more effective than Pap test in preventing cervical cancer. HPV as primary test will imply longer intervals and a triage test for HPV positive women. It will also permit the development of self-sampling devices. These innovations may affect population coverage, participation, and compliance to protocols, and likely in a different way for less educated, poorer, and disadvantaged women.

Aim: To describe the impact on inequalities, actual or presumed, of the introduction of HPV-based screening.

Methods:The putative HPV-based screening algorithm has been analyzed to identify critical points for inequalities. A systematic review of the literature has been conducted searching PubMed on HPV screening coverage, participation, and compliance. Results were summarized in a narrative synthesis.

Results: Knowledge about HPV and cervical cancer was lower in women with low socioeconomic status and in disadvantaged groups. A correct communication can reduce differences. Longer intervals will make it easier to achieve high-population coverage, but higher cost of the test in private providers could reduce the use of opportunistic screening by disadvantaged women. There are some evidences that inviting for HPV test instead of Pap increases participation, but there are no data on social differences. Self-sampling devices are effective in increasing participation and coverage. Some studies showed that the acceptability of self-sampling is higher in more educated women, but there is also an effect on hard-to-reach women. Communication of HPV positivity may increase anxiety and impact on sexual behaviors, the effect is stronger in low educated and disadvantaged women. Finally, many studies found indirect evidence that unvaccinated women are or will be more probably under-screened.

Conclusion: The introduction of HPV test may increase population coverage, but noncompliance to protocols and interaction with opportunistic screening can increase the existing inequalities.

Keywords: human papillomavirus, mass screening, social inequalities, participation, coverage, compliance

\section{BACKGROUND}

Cervical cancer is still the fourth cancer worldwide in terms of incidence, although the burden of disease is not evenly distributed, with about $80 \%$ of cases occurring in low-income countries (1). In industrialized countries, instead, incidence and mortality have been dramatically reduced thanks to Pap test and screening programs $(2,3)$. In fact, the Pap test is able to identify cytological abnormalities exfoliated from pre-cancerous lesions, and progression to cervical cancer is prevented through outpatient treatment $(2,3)$.

Persistent infection with HPV oncogenic types has been demonstrated to be the necessary, but not sufficient, cause of cervical cancer (3). Knowledge of the natural history of the disease has led to the introduction of two new tools for cervical cancer prevention: vaccine and HPV test for screening (4).

Population-based randomized trials have shown that screening with HPV as primary test is more effective than Pap test in reducing cervical cancer incidence (5) and mortality (6).

The accuracy characteristics of the HPV DNA test are different from those of the Pap test. First and foremost, the former is more sensitive and less specific (7). Further, it has a higher prospective negative predictive value, i.e., the risk of having a CIN3 or cancer 5 years after an HPV-negative test is still lower than the risk 3 years after a negative Pap test $(5,8)$. Due to lower specificity a higher number of women will need further ascertainment. However, few of them will have a high-grade lesion and direct 
referral to colposcopy may thus be too intensive an approach (911). On the other hand, higher sensitivity and prospective negative predictive value will allow longer intervals $(5,8)$. HPV infection can persist for several years before its clearance or progression to a high-grade lesion requiring treatment; women with longterm persistent infections need to be followed up with reasonable protocols, adapted to their risk of developing cancer (12).

Therefore the shift from Pap test to HPV test as a primary screening test will dramatically change the screening program protocols and organization: the intervals will be longer, and a triage test for HPV positive women and more complex algorithms for the management of positive women will be needed. Furthermore, the introduction of HPV test will result in less intensive protocols and follow up. Finally, a molecular test makes it possible to develop self-sampling devices.

All these changes and technical innovations may affect screening participation and population coverage $(11,13)$, and most likely in a different way for less educated, poorer, and more disadvantaged women (14-16).

To date, only few countries have introduced the HPV test in the organized screening protocol and none has yet implemented such protocols at a national level; several countries have large-scale population-based pilot projects under way (17-21).

\section{OBJECTIVE}

To identify the possible effect of the introduction of HPV-based protocols in organized screening program on social inequalities by means of an analysis of the process and of a systematic review of the literature. The analysis is focused on countries with public organized screening programs.

\section{METHODS}

\section{DEFINITION OF THE PUTATIVE ALGORITHM FOR HPV-BASED SCREENING}

After an initial search of the meta-literature (systematic reviews, HTA reports, guidelines, and narrative reviews) on implementing an HPV-based screening and social inequalities in cervical cancer prevention, we analyzed the putative screening algorithm with HPV as primary screening, as included in the up-coming European guidelines (9), to identify all the critical points where inequalities in coverage, participation, and compliance to protocols, and in the effectiveness of screening program could be generated or reduced.

\section{SCOPE}

To define the scope of the systematic review we analyzed the flowchart of the algorithm to identify those points where new inequalities might be introduced and/or where existing inequalities might be reduced. Relevant topics should have two characteristics: (1) there should be a noticeable change with the introduction of the HPV-based screening; (2) the topic should be potentially related to socioeconomic inequalities. Among the parameters measuring the effectiveness of an organized screening program, test coverage, participation, and compliance have a "per se" effect on equity (9).

\section{SYSTEMATIC REVIEW}

Literature search

A systematic review of the literature was conducted on PubMed and the European public screening program websites to identify relevant publications on HPV screening and coverage, participation, and compliance.

The PubMed search strategy was defined according to the methods used in two previous systematic reviews, one on the methods to increase participation in screening $(9,22,23)$ the other on inequalities and screening (24). To the original search of the systematic review on methods to increase participation we added terms to identify those focusing on inequalities as well as terms to specify HPV-based screening (HPV or human papillomavirus). The references of all the relevant papers were checked to identify other potentially relevant papers.

The search was limited to the period from $1 / 1 / 2000$ to $31 / 7 / 2013$. The rationale for limiting the search to 2000 is that in the 1990s there were no population-based experiences of HPV screening. Furthermore, the screening algorithms now proposed in organized screening were defined in the early 2000s (25).

\section{Inclusion criteria}

From the studies retrieved, we first selected those that were potentially relevant by reading the abstract. The abstract should present data or hypothesis on association or interaction between HPV knowledge, HPV screening attendance, and/or attitude and social, cultural, economic, and/or ethnic inequalities.

Due to resource limitations, the title and abstract screening was carried out by only one researcher (Flavia Baldacchini) and subsequently checked by a second author (Paolo Giorgi Rossi) by crosschecking the references. The full text of the relevant studies were then analyzed to identify and classify the information or hypothesis reported. A further number of studies was excluded in this step because the discussion of HPV and inequalities was too vague or because the paper focused exclusively on vaccination campaigns. The inclusion criteria were evaluated by two authors independently (Flavia Baldacchini and Paolo Giorgi Rossi); discordant cases were discussed to reach an agreement.

We did not perform any quality analysis since we were interested in identifying any issues that may be relevant, which could emerge even in low-quality papers.

\section{Data extraction and narrative synthesis}

From each paper the following data were extracted: publication year, author, title, topic(s) analyzed, outcome considered, study design, population, synthesis of results, and synthesis of the authors' conclusions.

Information from the selected papers was extracted according to its relevance with the topics listed in the flowchart analysis. Topics that emerged from the literature search and not postulated in the flowchart analysis were also identified and reported in the results. The papers were also classified according to the outcome considered: knowledge, test coverage, screening attitude and/or screening participation, compliance to protocols, and anxiety. In addition, we considered papers concerning the interactions between vaccine and screening.

Systematic review results are summarized in a narrative synthesis. 


\section{RESULTS}

\section{FLOWCHART ANALYSIS AND SEARCH RESULTS}

The critical points reported in Figure 1 were identified in the preliminary analysis of the meta-literature. They can be grouped into four main topics: test coverage of the population, participation in screening program, compliance to the screening protocols and referral strategies, and communication of positive results and related anxiety. Of the papers treating the effects on test coverage and screening participation, a relevant number focused on the possible use of self-sampling. Furthermore, two topics not directly linked to the screening protocol were identified: knowledge and communication strategies of HPV and the interaction between screening and HPV vaccine.

One hundred and forty-nine abstracts were initially identified. Of these, 121 were considered relevant, with 86 included after full text examination (Figure 2). During the literature analysis we summarized the information reported by each study according to the general issue for which it was relevant (Figure 1).

\section{KNOWLEDGE AND COMMUNICATION STRATEGIES}

The systematic review identified 23 studies on knowledge about HPV that reported differences in socio-economic status levels or interaction between SES and effectiveness of information/communication tools or strategies.

In general, the more deprived women, with lower educational level or SES, and women in more disadvantaged ethnic groups knew less about HPV and cervical cancer risk. Vanslyke and colleagues (26) found that knowledge of HPV was generally very limited among Hispanic women aged 18-60. Furthermore, an indirect evidence of inequality among Hispanics came from the comparison of the Health Interview National Trends Survey (HINTS) and a cross-section of callers to the National Cancer Institute's (NCI) cancer information service (CIS) (27). Luque and colleagues (42) observed greater awareness of HPV and the HPV vaccine among Anglo American and Puerto Rican women than among Mexican and Honduran women. Al-Naggar and colleagues (28) examined the level of knowledge and barriers against

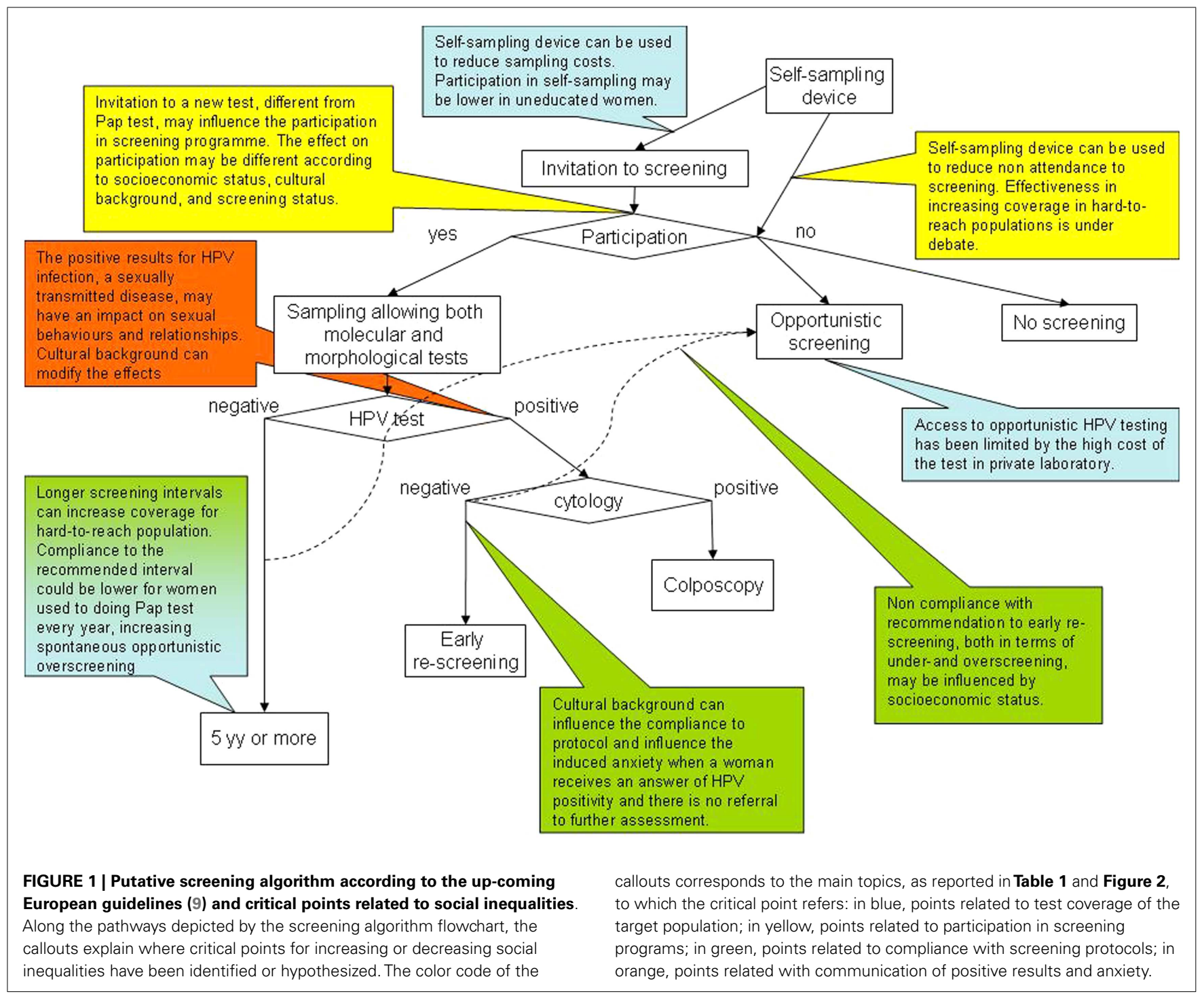




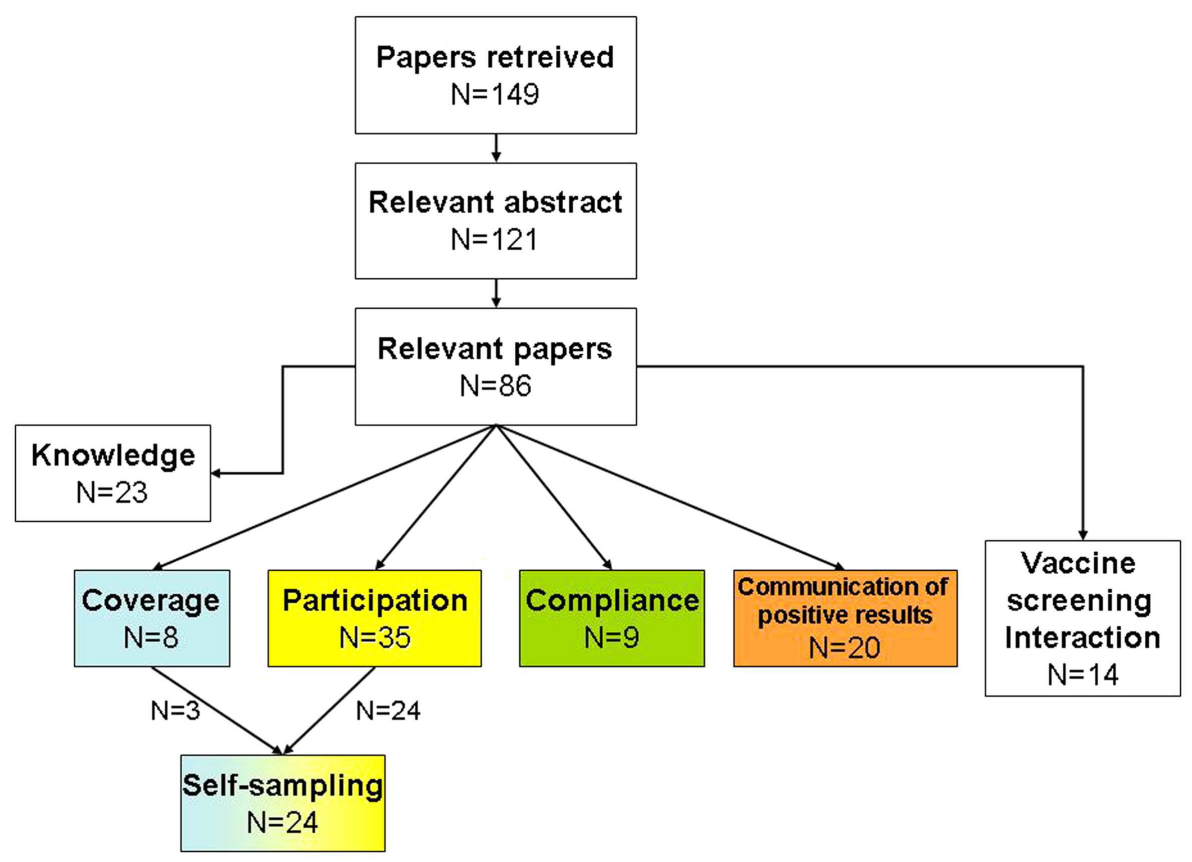

FIGURE 2 | Flowchart of the systematic search. The color code of the main topics is the same as reported in Figure $\mathbf{1 .}$

cervical cancer screening of female university students in Selangor, Malaysia and found that age, marital status, ethnicity, and monthly family income, were significantly associated with knowledge of cervical cancer screening. Vogtmann and colleagues (29) evaluated the demographic and behavioral factors associated with HPV awareness and knowledge in a population of Mexican college students and found that characteristics associated with not having heard about HPV were being male, not having running water, not having health insurance, and not having sexual experience. In the UK, Waller and colleagues (30) found that women and more educated people had better knowledge of the established risk factors for cervical cancer and HPV and in Germany, Klug and colleagues (33) found an association with social class. Only one study on Turkish sexual workers found almost no association between HPV knowledge and educational level (34).

Most of the studies were conducted before the introduction of HPV vaccine. Indeed, it is very likely that the knowledge and awareness of HPV strongly increased in the years around the introduction of mass vaccination campaigns in 2007-2009. This was confirmed by some focus groups conducted with women participating in the Florence, Italy cervical cancer screening in 2007 and $2011(35,36)$. It is also likely that the increase in knowledge was more relevant for less educated women who started out with a lower level of knowledge. Nevertheless, the PREGIO study, conducted in Italy during the launch of the mass vaccination of 12-year-old girls in 2008, found that knowledge of Pap test was still greater than the knowledge of HPV and cervical cancer, although more than $70 \%$ correctly answered questions on virus transmission and the role of HPV in cancerogenicity (37). Women with higher educational level had greater knowledge about HPV and cervical cancer prevention but had similar attitudes toward undergoing vaccination. Two recent studies conducted in France (38) and Germany (39), instead, found there was still very little knowledge (16\%) of the link between HPV and cervical cancer and an insufficient HPV awareness and low vaccination prevalence among young women.

Three trials and one case-control study compared different strategies to provide information on HPV. Lloyd and colleagues (43) observed an increase in knowledge in 13-16-year-old girls with an increase in fear but not in anxiety about infections after the distribution of a leaflet (not specific for HPV test and including other sexually transmitted diseases as well). Similar results were observed by Papa and colleagues (44) in women undergoing an HPV test and by Marek and colleagues (45) after a brief HPVoriented program for adolescent. A limit of these two studies was the absence of information about SES. Wetzel and colleagues (46) evaluated the efficacy of a short counseling program and observed an increase in knowledge. The intervention was effective in reducing the existing differences between black and white women and between those with Medicaid and those with private insurance.

Other authors have tried to provide insights into effective communication about HPV, but with little supporting evidence (47, 48 ) and no mention of how to reduce SES inequalities.

\section{COVERAGE OF THE TARGET POPULATION}

Longer intervals will influence the test population coverage because the definition of test coverage will change, but also because there may be an impact on women's behaviors and attitude. There are no direct evidences, experimental or observational, in the literature on this point.

Most of the literature is only speculative. Our systematic review retrieved eight studies on coverage and HPV-based screening that 
Table 1 | Summary of the questions and results emerged from the systematic review.

\begin{tabular}{|c|c|c|}
\hline Topic & Reference & Question \\
\hline \multirow[t]{2}{*}{ Knowledge } & $(26-42)$ & Differences in knowledge \\
\hline & $(43-48)$ & $\begin{array}{l}\text { Effective tools to improve knowledge and } \\
\text { reduce inequalities }\end{array}$ \\
\hline \multirow[t]{3}{*}{ Coverage } & $(16,49-51)$ & $\begin{array}{l}\text { Longer screening intervals can increase the } \\
\text { coverage for hard-to-reach population }\end{array}$ \\
\hline & $(9,52)$ & $\begin{array}{l}\text { Access to opportunistic HPV testing could be } \\
\text { limited by the high cost of the test in private } \\
\text { laboratories }\end{array}$ \\
\hline & $(49,53,54)$ & $\begin{array}{l}\text { Self-sampling device could be used to reduce } \\
\text { sampling costs, but could affect coverage }\end{array}$ \\
\hline
\end{tabular}

Participation $(9,13,16,17,21$, The proposal of a new test may change the

$26,32,50,52,53$, participation

$55-57)$

Longer intervals could disrupt the habits, thereby of women reducing participation

(14, 22, 49, 53-55, 58-75)

Self-sampling device could be used to participation in screening program

Compliance

(41)

to screening

protocols

$(9,21,35,36,57)$

$(17,21,76,77)$

Communication $(2,9,78-81)$

of positive

results

$(32,40,79,80$ 82-84)

$(31,36,84-91)$

Interaction

$(38,92-98)$

vaccine and

screening
(56, 99-103)
Longer intervals could increase opportunistic over-screening

Referral to early rescreen after HPV positive cytology-negative test could increase use of unnecessary ascertainment

Referral to early rescreen after HPV positive cytology-negative test could result in substantial loss to follow up

Communication of HPV positivity can induce anxiety

Communication of HPV positivity can induce changes in sexual habits

Effective ways to reduce anxiety and other adverse effects

Negative effect of vaccine on future screening

Association between vaccine and screening attitudes

\section{Summary of the results}

Almost all studies found a gradient in knowledge about HPV and cervical cancer with any of the variables used to measure SES or deprivation: educational level, disadvantaged groups, etc

Differences tend to diminish after any kind intervention to inform women. Results about written material are inconclusive; short counseling showed to be effective

No data are available

No data are available

Only one trial conducted in Mexico. A lower coverage was achieved, but it was due to women not found at home and to whom the self-sampling was not mailed

Several observational studies and one trial found a small increase in participation when invited for a HPV test compared to Pap test. No data on how it will impact on inequalities

No data are available

Nine studies showed a positive effect of self-sampling in under-screened population. Some studies showed that the device is acceptable also among disadvantage women, even in some case to a minor extent

No data are available

No data are available

The compliance to early rescreen in this group of women varied among studies, showing that correct communication can reduce loss to follow up. No data about differences in socio-economic status are available

Several studies showed anxiety after the communication of Pap test and/or HPV positivity. Women with higher educational level are advantaged in understanding the gynecologist's and midwife's recommendations and explanations

Some studies showed concern about the sexual transmission of the virus. These concerns were stronger in women of lower educational level and disadvantaged ethnic groups

Face-to-face counseling was preferred by women, but cannot be used only for positive results because of the anxiety caused by the understanding that the test was positive and the need to wait for the counseling. Short phone counseling only for positive was also appreciated

Only one studies reported a small proportion of girls referring that vaccination would change their attitude to screening

Several studies showed an association between vaccine and screening attitude or between vaccination and screening coverage in mothers. Results are heterogeneous 
treated social inequalities. Some authors speculated on the effect of longer intervals, and the two options are reported $(16,49-51)$ : longer intervals can facilitate achieving high-population coverage; longer intervals may disrupt women's habits and thus have detrimental effects on coverage. The second hypothesis is usually supposed to affect especially deprived women (16).

Many countries have a mixed model with opportunistic and organized screening existing together and sometimes competing for participation $(104,105)$. Only two documents mention the consequences on social inequalities of the interaction between spontaneous and organized screening in the era of HPV-based screening $(9,52)$. The introduction of HPV as primary screening test may have some consequences in this context and can surely change the inequality scenario: in the opportunistic setting, HPV will be much more expensive than Pap test, at least in the short term. If opportunistic screening offers the two options, less wealthy women will be pushed to undergo Pap test and richer ones HPV, regardless of what would be more appropriate. If the diffusion of HPV testing in the opportunistic setting were stronger and the offer of Pap almost disappeared, the coverage in less wealthy women would decrease or these women would be induced to participate in organized screening programs. Finally, if the screening programs are reinforced by the introduction of HPV testing, it is likely that inequalities will decrease, as already observed in countries with well-established organized screening programs for cervical and breast cancer (106).

\section{PARTICIPATION IN SCREENING PROGRAM}

The proposal of a new test may influence attendance. Thirty-five studies were found, but only one trial (53) and three intervention studies with historical controls $(17,21,50)$ compared the participation in HPV-based vs. cytology-based screening program. The only trial (53) focused on self-sampling, but used as control groups both standard invitation to have a Pap test at the clinic and an invitation to have an HPV test at the clinic. The sample size was small and the population was selected to be non-responder to the first invitation, but it found an $8 \%$, non-significant increase in participation. Data from pilot studies showed in most cases a higher participation in HPV-based screening than in Pap testbased screening. In particular, two Italian studies showed a 10\% increase in coverage $(17,21)$. The increase was stronger in younger women, a group less covered than older women in Italy (17). Another study (50) found that after the initial diffidence, Hispanic and black women were more likely to undergo HPV test than were white women. Some other papers reported the results of pilot or demonstration studies but without any term of comparison. Levinson and colleagues (55) found high acceptability in underserved Peruvian women, Marlow and colleagues (56) found that, in contrast to screening attendance, ethnicity plays an important role in HPV testing, and finally, Philips and colleagues (13) report that adding HPV-based triage to the Pap program lowered the value of screening participation for only two women, whereas for the sample as a whole, it increased the average valuation by about $47 \%$.

It is difficult to predict what impact the increase in participation will have on test coverage, but the increased costs in opportunistic screening and the increased appeal of programs offering the
HPV test will probably increase participation in organized screening. Part of this increase will probably involve some women who are under- or never-screened, which will result in a substantial reduction in inequality of access and in the burden of disease (107).

\section{USE OF SELF-SAMPLING DEVICES}

Self-sampling devices can be used to increase coverage and/or participation among non-responders. Twenty-four studies treated the effect of self-sampling on coverage or participation. Nine trials $(53,54,58,60-65)$ and four reviews $(22,66-68)$ found a positive effect of direct home mailing of the device, while other ways of offering the device are not effective (53). Among studies reporting the acceptability of self-sampling among women, one showed that it was higher among married women and less accepted by some ethnic groups, such as Asians in the UK (69) and another found (73) that it was higher among those with some or more college education (43 vs. $26 \%$ ), and among those who were not Hispanic compared to Hispanic ( 49 vs. $28 \%$ ). However, four studies found high acceptability also in the most hard-to-reach women $(67,70$, $71,74)$. One of the main concerns in women performing selfsampling is not collecting an adequate sample $(53,69,72,75)$. This concern is stronger among Indian and African Caribbean women than among white British women (75). In particular, two trials in France conducted in two neighborhoods with different socioeconomic levels $(62,64)$ measured the difference in effectiveness of self-sampling in increasing coverage: they observed that the relative risk of having a test was higher in low socio-economic status women but that the impact was limited in both contexts due to low participation and very low compliance to colposcopies in positive women. A study in the Netherlands (59), found that self-sampling was effective in increasing coverage among under-covered populations, but the response rate was higher in native-Dutch women and in women who already had a previous Pap test. Another study, conducted in central Italy, found no effect of self-sampling in a rural area and a relevant effect in urban areas (53), while a Swedish study found no difference in acceptance in different SES levels (108). These studies, designed to test self-sampling as a tool to improve Pap test-based programs, suggest that the most deprived women, even in HPV-based programs, will have more difficulty accepting self-sampling, but an increase in compliance can be obtained in most of the socio-economic groups.

Self-sampling devices can also be used to reduce sampling costs, though it could influence participation. Only one large trial in Mexico (49) tested self-sampling as first approach method and showed a lower participation for self-sampling than for Pap test when all the population was included in the analyses. If, however, we exclude women not found at home and to whom the selfsampling device was not mailed, the participation was over $98 \%$. Such a result has the potential to eliminate any inequality in access to screening, providing we have complete lists of resident women with updated and accurate addresses.

\section{COMPLIANCE TO SCREENING PROTOCOLS}

Nine papers treated the differences in compliance with respect to HPV-related protocols.

Compliance to a 5-year interval after HPV-negative test may be low for women used to having a Pap test every year (41), 
thereby increasing spontaneous opportunistic over-screening. No published data were found about compliance to the recommended interval after HPV. Previous studies found an association between intervals shorter than recommended and high socio-economic status women $(109,110)$. Consequently, if over-screening increases, the phenomenon will probably be less relevant for deprived women.

Non-compliance with the recommendation to repeat test after 1 year (or 6 months), both in terms of under- and over-screening, may be influenced by socio-economic status. It has been observed that women have an overwhelming preference for immediate colposcopy rather than continued surveillance for persistent HPV (57). Cultural background can influence the compliance to protocol and increase or decrease the induced anxiety when a woman receives a result of HPV positivity and there is no immediate referral to further assessment.

Some authors considered the implication of effective communication of the test results on compliance to 1-year follow up (9, 21). The implications differ depending on whether it is necessary to invite the women back to collect a cytologic sample or whether the sampling method allows reflex cytology in to be performed (a liquid-based cytology or a double sampling taken at the same moment). In the first case, high compliance is needed to obtain the second sample. If the Pap test is negative, women who are HPV positive and Pap test negative must be reassured about waiting 1 year before repeating the test so as to avoid unnecessary colposcopies or other evaluations during that period. In the case of a reflex cytology test, we can give the HPV and cytology results at the same time, leaving only the problem of reassuring women for the 1-year follow up. Compliance to protocols varied dramatically among trials and pilot studies results, with some programs obtaining more than $85 \%$ without any particular interventions (17) and other pilot studies (21) and trials with relevant loss to follow up in HPV positive women $(76,77)$ when colposcopy was delayed. In some cases there was an evidence of over-screening (21), but there are no data on SES differences. In a non-randomized study, a brief phone counseling at the moment of HPV positivity strongly increased the compliance (65 vs. $35 \%$ ) to 1-year follow up (21).

All the problems related to compliance to recommended protocols are more critical when a strong opportunistic offer is present $(52,111)$, in particular when there is a risk of overuse of screening test (i.e., shorter intervals or extra Pap test in HPVnegative women) and of evaluations (i.e., extra colposcopies in HPV positive cytology-negative women). In fact, in opportunistic screening gynecologists usually recommend a yearly Pap test and women are used to shorter intervals than that recommended by organized screening. In some focus groups $(35,36)$, a certain diffidence against longer intervals emerged when proposed by the public health system because it was perceived as a budget cut rather than a measure to avoid overtreatment (112). Even if this sort of skepticism may be present in all cultural and economic strata of society, the effect on compliance will probably be greater among women with higher SES because they undergo regular gynecological exams more frequently than do women with low SES.

The only way to reduce negative interactions between organized and opportunistic screening during the HPV screening implementation is to reduce discrepancies between organized program protocols and the attitudes/recommendations of gynecologists and general practitioners working outside the program, be they public or private providers. How to achieve this is beyond of the scope of this paper, but education and participation in the definition of local protocols, within the limits imposed by the evidence, are necessary steps in the process $(113,114)$.

\section{COMMUNICATION OF POSITIVE RESULTS AND RELATED ANXIETY}

Finally, the communication of HPV infection positivity poses new problems combining the anxiety and the implications related to a sexually transmitted disease with that related to cancer $(79,80)$. We found 20 papers on the communication of positive results and how a woman's socio-economic status can affect how she receives it.

Previous systematic review $(2,9,78)$ found that communicating the result of an abnormal Pap smear may induce anxiety, fear of malignancy, difficulties in sexual intercourse, a different perception of the body, and fear of becoming infertile (115-118). Furthermore, some women reported fear of pain caused by colposcopy and treatment, which may cause loss to follow up (117). One paper shows that the anxiety induced by positive Pap test results (81) was stronger in women with low socio-economic status. Indeed, we can suppose that many of the feelings related to a positive result are determined by the woman's knowledge and ability to understand the midwife's or gynecologist's indications, which is almost certainly associated with her educational level. All these concerns are also valid in HPV-based screening and may be even more intense given the higher proportion of positive women (82). Furthermore, there are concerns that are unique to HPV-based screening: since this test explicitly targets a sexually transmitted virus, positivity may have an impact on sexual behaviors and relationships $(40,82)$. This concern has been shown to be higher in low education level women and non-white ethnic groups in the UK (32), and more in general, to women's social status (married vs. unmarried), sexual history (number of partners), cultural background (sexual norms and practices), and knowledge and understanding of the link between HPV and cancer (83). Several studies dealing with this found that current and past relationships, cultural norms concerning sexual habits, and knowledge of HPV and cervical cancer were possible modifiers of the psychological response to a positive result (82). Two studies using focus groups to evaluate the health education material and response letters of a pilot screening program found that the women asked for shorter texts and simpler wording; the greatest concerns were related to the difficulty in understanding the real risk of cancer $(36,87)$. Finally, Waller et al. (31) concluded that the way in which information is presented to women may be crucial in minimizing the negative psychological impact of testing positive and ensuring that participation in screening remains high.

Eight studies analyzed the health information needs of women undergoing an HPV test and in particular, of those receiving a result of positivity (84-91). Only one, based on Pap test experience, reports the results of different communication strategies. However, given the low number of participants (20 women), the authors could not determine whether effectiveness was associated with SES. Women questioned whether communicating results by letter would violate their privacy and generally preferred receiving 
a phone call because it permits immediate clarification, thereby reducing anxiety. The most preferred mode was face-to-face communication, for negative and positive results alike. In fact, they were worried that a differentiated mode of communication (letter for negative results and face-to-face for positive results) would increase their anxiety because the amount of time that elapsed from the date of the appointment would implicitly mean a positive result, to be confirmed or not during the counseling itself (84).

Obviously, a phone call and face-to-face communication make it possible to modulate the message according to the woman's coping, linguistic abilities, and educational level. However, there are two main obstacles to implementing face-to-face communication: it is very time-consuming and, to avoid increasing anxiety, it should be done for both negative and positive results.

\section{VACCINE AND SCREENING INTERACTION}

One of the most treated topics in the literature was the interaction between vaccination and screening, with 14 papers directly reporting data on this topic. Two main points were treated: (1) the effect of vaccination on women's attitude to screening and consequently on test coverage (92-94, 96-98), the hypothesis is that being vaccinated could change future participation in screening [usually the authors suggest a decrease - Ref. $(93,94)$ ]; (2) the association between vaccination and future screening attitude (56, 99-102), i.e., those girls who do not do the vaccination now are probably those who will not participate in screening in the future. The consequence is that the impact on cervical cancer screening of vaccinated cohorts will be minimal because most cancers will occur in women not vaccinated and not screened (95). These two phenomena are not typical of the HPV-based screening and most of the literature considered the relation between vaccination and Pap test use.

The first point has been treated by Brotherton and colleagues, with interviews to girls to whom vaccination had been proposed: only $8 \%$ said that HPV vaccine could have a negative effect on their future screening habits.

As for the second point, two study designs have been used: attitude interviews to vaccinated and unvaccinated girls already in or close to the screening target age (99, 103); for younger girls, the association between the mother's Pap test use and the daughter's vaccination state $(56,100,101)$. The results are mixed: two studies $(56,99)$ found no association while the others found a strong association between vaccination and screening (99) or between mother's participation in screening and her daughter's being vaccinated (100-102).

None of the studies hypothesized how the introduction of HPV test might modify these phenomena. Only the study by Marlow and colleagues explicitly measured attitudes to HPV testing.

The general opinion is that HPV should be the primary screening test in vaccinated cohorts (119) and research on vaccine and screening interaction should be directed to define the best screening algorithms for vaccinated women.

\section{CONCLUSION}

Since equity in access is one of the main objectives of organized screening programs, the introduction of HPV test may be a way to increase population coverage and thus finally include some of the hard-to-reach women. Interactions with spontaneous screening may increase over-screening and inappropriate use of evaluation tests although this phenomenon is likely to be more relevant among women with higher socio-economic status.

There remain, however, problems concerning how to communicate positive results, control induced anxiety, and reduce noncompliance to protocols, which may augment existing inequalities if particular attention is not paid to effective communication.

\section{ACKNOWLEDGMENTS}

Part of the systematic review has been conducted with the contribution of the Italian Ministry of Health, Centro per la Prevenzione e il Controllo delle Malattie Project "Implementazione dei programmi di screening nel Sud Italia: analisi delle barriere e dei fattori facilitanti, modificabili e non.” Included in the National Prevention Plan 2010 2012. We thank Jacqueline Costa for the English editing.

\section{SUPPLEMENTARY MATERIAL}

The Supplementary Material for this article can be found online at http://www.frontiersin.org/Journal/10.3389/fonc.2014. 00020/abstract

\section{REFERENCES}

1. IARC. Globocan. Cancer Fact Sheet: Cervical Cancer Estimated Incidence, Mortality and Prevalence Worldwide in 2012. (2012). Available from: http: //globocan.iarc.fr/Pages/fact_sheets_cancer.aspx descriptive epidemiology

2. Arbyn M, Anttila A, Jordan J, Schenck U, Ronco G, Segnan N, et al., editors. European Commission. European Guidelines for Quality Assurance in Cervical Cancer Screening. 2nd ed. Luxembourg: Office for Official Publications of the European Communities (2008). p. 1-291.

3. IARC Working Group on the Evaluation of Cancer Preventive Strategies. Handbooks of cancer prevention. Cervix Cancer Screening. (Vol. 10), Lyon: IARC (2005). p. 1-302.

4. zur Hausen H. Papillomaviruses and cancer: from basic studies to clinical application. Nat Rev Cancer (2002) 2(5):342-50. doi:10.1038/nrc798

5. Ronco G, Dillner J, Elfström KM, Tunesi S, Snijders PJF, Arbyn M, et al. Efficacy of HPV-based screening for preventing invasive cervical cancer: follow-up of European randomised controlled trials. Lancet (2013). doi:10.1016/S01406736(13)62218-7. [Epub ahead of print].

6. Sankaranarayanan R, Nene BM, Shastri SS, Jayant K, Muwonge R, Budukh AM, et al. HPV screening for cervical cancer in rural India. N Engl J Med (2009) 360(14):1385-94. doi:10.1056/NEJMoa0808516

7. Cuzick J, Arbyn M, Sankaranarayanan R, Tsu V, Ronco G, Mayrand MH, et al. Overview of human papillomavirus-based and other novel options for cervical cancer screening in developed and developing countries. Vaccine (2008) 26(Suppl 10):K29-41. doi:10.1016/j.vaccine.2008.06.019

8. Dillner J, Rebolj M, Birembaut P, Petry KU, Szarewski A, Munk C, et al. Longterm predictive values of cytology and human papillomavirus testing in cervical cancer screening: joint European cohort study. BMJ (2008) 337:a1754. doi:10.1136/bmj.a1754

9. Ronco G, Biggeri A, Confortini M, Naldoni C, Segnan N, Sideri M, et al. Health technology assessment report: HPV DNA based primary screening for cervical cancer precursors. Epidemiol Prev (2012) 36(3-4 Suppl 1):e1-72.

10. Health Council of the Netherlands. Population Screening for Cervical Cancer. The Hague: Health Council of the Netherlands (2011).

11. Cuzick J, Bergeron C, von Knebel Doeberitz M, Gravitt P, Jeronimo J, Lorincz AT, et al. New technologies and procedures for cervical cancer screening. Vaccine (2012) 30(Suppl 5):F107-16. doi:10.1016/j.vaccine.2012.05.088

12. Castle PE, Sideri M, Jeronimo J, Solomon D, Schiffman M. Risk assessment to guide the prevention of cervical cancer. J Low Genit Tract Dis (2008) 12(1):1-7. doi:10.1097/lgt.0b013e31815ea58b

13. Philips Z, Avis M, Whynes DK. Introducing HPV triage into the English cervical cancer screening program: consequences for participation. Women Health (2006) 43(2):17-34. doi:10.1300/J013v43n02_02 
14. Lazcano Ponce E, Allen-Leigh B. Innovation in cervical cancer prevention and control in Mexico. Arch Med Res (2009) 40(6):486-92. doi:10.1016/j.arcmed. 2009.07.007

15. Scarinci IC, Garcia FA, Kobetz E, Partridge EE, Brandt HM, Bell MC, et al. Cervical cancer prevention: new tools and old barriers. Cancer (2010) 116(11):2531-42. doi:10.1002/cncr.25065

16. Bekkers RL, Meijer CJ, Massuger LF, Snijders PJ, Melchers WJ. Effects of HPV detection in population-based screening programmes for cervical cancer; a Dutch moment. Gynecol Oncol (2006) 100(3):451-4. doi:10.1016/j.ygyno. 2005.10.020

17. Zorzi M, Del Mistro A, Farruggio A, de'Bartolomeis L, Frayle-Salamanca H, Baboci L, et al. Use of a high-risk human papillomavirus DNA test as the primary test in a cervical cancer screening programme: a population-based cohort study. BJOG (2013) 120(10):1260-7. doi:10.1111/1471-0528.12272

18. National Health System Cervical Screening Programme (NHSCSP). HPV Primary Screening Pilot Announced. (2012). Available from: http://www. cancerscreening.nhs.uk/cervical/news/021.html

19. Rijkaart DC, Berkhof J, van Kemenade FJ, Coupe VM, Rozendaal L, Heideman DA, et al. HPV DNA testing in population-based cervical screening (VUSAScreen study): results and implications. Br J Cancer (2012) 106(5):975-81. doi:10.1038/bjc.2011.581

20. Leinonen MK, Nieminen P, Lönnberg S, Malila N, Hakama M, Pokhrel A, et al. Detection rates of precancerous and cancerous cervical lesions within one screening round of primary human papillomavirus DNA testing: prospective randomised trial in Finland. BMJ (2012) 345:e7789. doi:10.1136/bmj.e7789

21. Confortini M, Giorgi Rossi P, Barbarino P, Passarelli AM, Orzella L, Tufi MC. Screening for cervical cancer with the Human papillomavirus test in an area of central Italy with no previous active cytological screening program. J Med Screen (2010) 17(2):79-86. doi:10.1258/jms.2010.009092

22. Camilloni L, Ferroni E, Jimenez Cendales B, Pezzarossi A, Furnari G, Borgia $\mathrm{P}$, et al. Methods to increase participation in organised screening programs: a systematic review. BMC Public Health (2013) 13:464. doi:10.1186/1471-245813-464

23. Ferroni E, Camilloni L, Jimenez B, Furnari G, Borgia P, Guasticchi G, et al. How to increase uptake in oncologic screening: a systematic review of studies comparing population-based screening programs and spontaneous access. Prev Med (2012) 55(6):587-96. doi:10.1016/j.ypmed.2012.10.007

24. Spadea T, Bellini S, Kunst A, Stirbu I, Costa G. The impact of interventions to improve attendance in female cancer screening among lower socioeconomic groups: a review. Prev Med (2010) 50(4):159-64. doi:10.1016/j.ypmed.2010. 01.007

25. Cuzick J, Szarewski A, Cubie H, Hulman G, Kitchener H, Luesley D, et al. Management of women who test positive for high-risk types of human papillomavirus: the HART study. Lancet (2003) 362(9399):1871-6. doi:10.1016/ S0140-6736(03)14955-0

26. Vanslyke JG, Baum J, Plaza V, Otero M, Wheeler C, Helitzer DL. HPV and cervical cancer testing and prevention: knowledge, beliefs, and attitudes among Hispanic women. Qual Health Res (2008) 18(5):584-96. doi:10.1177/ 1049732308315734

27. Kobetz E, Kornfeld J, Vanderpool RC, Finney Rutten LJ, Parekh N, O’Bryan G, et al. Knowledge of HPV among United States Hispanic women: opportunities and challenges for cancer prevention. J Health Commun (2010) 15(Suppl 3):22-9. doi:10.1080/10810730.2010.522695

28. Al-Naggar RA, Low WY, Isa ZM. Knowledge and barriers towards cervical cancer screening among young women in Malaysia. Asian Pac J Cancer Prev (2010) 11(4):867-73.

29. Vogtmann E, Harlow SD, Valdez AC, Valdez JC, Ponce EL. HPV knowledge in Mexican college students: implications for intervention programmes. Health Soc Care Community (2011) 19(2):148-57. doi:10.1111/j.1365-2524. 2010.00954.x

30. Waller J, McCaffery K, Wardle J. Beliefs about the risk factors for cervical cancer in a British population sample. Prev Med (2004) 38(6):745-53. doi:10.1016/j.ypmed.2004.01.003

31. Waller J, McCaffery K, Nazroo J, Wardle J. Making sense of information about HPV in cervical screening: a qualitative study. Br J Cancer (2005) 92(2): 265-70.
32. Waller J, Marlow LA, Wardle J. Anticipated shame and worry following an abnormal Pap test result: the impact of information about HPV. Prev Med (2009) 48(5):415-9. doi:10.1016/j.ypmed.2008.11.004

33. Klug SJ, Hetzer M, Blettner M. Screening for breast and cervical cancer in a large German city: participation, motivation and knowledge of risk factors. Eur J Public Health (2005) 15(1):70-7. doi:10.1093/eurpub/cki118

34. Ersan G, Köse S, Gunes H, Ozkan M. Knowledge and awareness of female sex workers towards human papillomavirus infection in Turkey. Cent Eur J Public Health (2012) 20(3):219-22.

35. Cogo C, Iossa A. Triage di ASCUS con HPV: revisione del materiale informativo mediante gruppi focus con utenti. In: Rosselli del Turco M, Mantellini P, editors. CSPO - Istituto Scientifico Prevenzione Oncologica. I Programmi di Screening Della Regione Toscana. Settimo Rapporto Annuale. Firenze: Dicembre (2006). p. 107-21

36. Iossa A. La Comunicazione 3 Seminario Nazionale HPV, Screening Carcinoma Della Cervice e Vaccini HPV. Firenze: Dicembre (2010).

37. Donati S, Giambi C, Declich S, Salmaso S, Filia A, Ciofi degli Atti ML, et al. Knowledge, attitude and practice in primary and secondary cervical cancer prevention among young adult Italian women. Vaccine (2012) 30(12):2075-82. doi:10.1016/j.vaccine.2012.01.057

38. Haesebaert J, Lutringer-Magnin D, Kalecinski J, Barone G, Jacquard AC, Régnier $\mathrm{V}$, et al. French women's knowledge of and attitudes towards cervical cancer prevention and the acceptability of HPV vaccination among those with 14-18 year old daughters: a quantitative-qualitative study. BMC Public Health (2012) 12:1034. doi:10.1186/1471-2458-12-1034

39. Kuznetsov AV, Müller RA, Ruzicka T, Herzinger T, Kuznetsov L. Knowledge of sexually transmitted HPV infection, genitoanal warts, cancer and their prevention among young females after vaccine introduction in Germany. J Eur Acad Dermatol Venereol (2013) 27(12):1527-34. doi:10.1111/jdv.12045

40. McCaffery K, Forrest S, Waller J, Desai M, Szarewski A, Wardle J. Attitudes towards HPV testing: a qualitative study of beliefs among Indian, Pakistani, African-Caribbean and white British women in the UK. Br J Cancer (2003) 88(1):42-6. doi:10.1038/sj.bjc.6600686

41. Ashok M, Berkowitz Z, Hawkins NA, Tangka F, Saraiya M. Recency of Pap testing and future testing plans among women aged 18-64: analysis of the 2007 Health Information National Trends Survey. J Womens Health (Larchmt) (2012) 21(7):705-12. doi:10.1089/jwh.2012.3562

42. Luque JS, Castañeda H, Tyson DM, Vargas N, Proctor S, Meade CD. HPV awareness among Latina immigrants and Anglo American women in the southern U.S.: cultural models of cervical cancer risk factors and beliefs. NAPA Bull (2010) 34(1):84-104. doi:10.1111/j.1556-4797.2010.01053.x

43. Lloyd GP, Marlow LA, Waller J, Miles A, Wardle J. An experimental investigation of the emotional and motivational impact of HPV information in adolescents. J Adolesc Health (2009) 45(5):532-4. doi:10.1016/j.jadohealth.2009.06. 003

44. Papa D, Moore Simas TA, Reynolds M, Melnitsky H. Assessing the role of education in women's knowledge and acceptance of adjunct high-risk human Papillomavirus testing for cervical cancer screening. J Low Genit Tract Dis (2009) 13(2):66-71. doi:10.1097/LGT.0b013e31818a53f0

45. Marek E, Dergez T, Rebek-Nagy G, Szilard I, Kiss I, Ember I, et al. Effect of an educational intervention on Hungarian adolescents' awareness, beliefs and attitudes on the prevention of cervical cancer. Vaccine (2012) 30(48):6824-32. doi:10.1016/j.vaccine.2012.09.012

46. Wetzel C, Tissot A, Kollar LM, Hillard PA, Stone R, Kahn JA. Development of an HPV educational protocol for adolescents. J Pediatr Adolesc Gynecol (2007) 20(5):281-7. doi:10.1016/j.jpag.2006.12.002

47. Tristram A. HPV information needs. Best Pract Res Clin Obstet Gynaecol (2006) 20(2):267-77. doi:10.1016/j.bpobgyn.2005.10.006

48. Dyson S, Pitts M, Lyons A, Mullins R. Providing high quality information about human papillomavirus for women after treatment for high-grade cervical dysplasia. Sex Health (2010) 7(1):49-54. doi:10.1071/SH09059

49. Lazcano-Ponce E, Lorincz AT, Cruz-Valdez A, Salmerón J, Uribe P, VelascoMondragón E, et al. Self-collection of vaginal specimens for human papillomavirus testing in cervical cancer prevention (MARCH): a community-based randomised controlled trial. Lancet (2011) 378(9806):1868-73. doi:10.1016/ S0140-6736(11)61522-5 
50. Price RA. Association between physician specialty and uptake of new medical technologies: HPV tests in Florida Medicaid. J Gen Intern Med (2010) 25(11):1178-85. doi:10.1007/s11606-010-1415-9

51. Tsu VD, Levin CE. Making the case for cervical cancer prevention: what about equity? Reprod Health Matters (2008) 16(32):104-12. doi:10.1016/S09688080(08)32411-2

52. Anttila A, Martin-Moreno JM. Cancer screening. In: Mackenbach J, McKee M, editors. Successes and Failures of Health Policy in Europe. Four Decades of Divergent Trends and Converging Challenges. Berkshire: McGraw-Hill, Open University Press (2013). p. 179-92.

53. Giorgi Rossi P, Marsili LM, Camilloni L, Iossa A, Lattanzi A, Sani C, et al. The effect of self-sampled HPV testing on participation to cervical cancer screening in Italy: a randomised controlled trial (ISRCTN96071600). Br J Cancer (2011) 104(2):248-54. doi:10.1038/sj.bjc.6606040

54. Gök M, Heideman DA, van Kemenade FJ, Berkhof J, Rozendaal L, Spruyt JW, et al. HPV testing on self collected cervicovaginal lavage specimens as screening method for women who do not attend cervical screening: cohort study. $B M J$ (2010) 340:c1040. doi:10.1136/bmj.c1040

55. Levinson KL, Abuelo C, Chyung E, Salmeron J, Belinson SE, Sologuren CV, et al. The Peru cervical cancer prevention study (PERCAPS): community-based participatory research in Manchay, Peru. Int J Gynecol Cancer (2013) 23(1):141-7. doi:10.1097/IGC.0b013e318275b007

56. Marlow LA, Waller J, Wardle J. Sociodemographic predictors of HPV testing and vaccination acceptability: results from a population-representative sample of British women. J Med Screen (2008) 15(2):91-6. doi:10.1258/jms.2008. 008011

57. Waller J, McCaffery K, Kitchener H, Nazroo J, Wardle J. Women's experiences of repeated HPV testing in the context of cervical cancer screening: a qualitative study. Psychooncology (2007) 16(3):196-204. doi:10.1002/pon.1053

58. Gök M, Heideman DA, van Kemenade FJ, de Vries AL, Berkhof J, Rozendaal L, et al. Offering self-sampling for human papillomavirus testing to nonattendees of the cervical screening programme: characteristics of the responders. Eur J Cancer (2012) 48(12):1799-808. doi:10.1016/j.ejca.2011.11.022

59. Gök M, van Kemenade FJ, Heideman DA, Berkhof J, Rozendaal L, Spruyt JW, et al. Experience with high-risk human papillomavirus testing on vaginal brush-based self-samples of non-attendees of the cervical screening program. Int J Cancer (2012) 130(5):1128-35. doi:10.1002/ijc.26128

60. Virtanen A, Nieminen P, Luostarinen T, Anttila A. Self-sample HPV tests as an intervention for nonattendees of cervical cancer screening in Finland: a randomized trial. Cancer Epidemiol Biomarkers Prev (2011) 20(9):1960-9. doi:10.1158/1055-9965.EPI-11-0307

61. Szarewski A, Cadman L, Mesher D, Austin J, Ashdown-Barr L, Edwards R, et al. HPV self-sampling as an alternative strategy in non-attenders for cervical screening - a randomised controlled trial. Br J Cancer (2011) 104(6):915-20. doi:10.1038/bjc. 2011.48

62. Piana L, Leandri FX, Le Retraite L, Heid P, Tamalet C, Sancho-Garnier H. HPV$\mathrm{Hr}$ detection by home self sampling in women not compliant with pap test for cervical cancer screening. Results of a pilot programme in Bouches-du-Rhône. Bull Cancer (2011) 98:723-31. doi:10.1684/bdc.2011.1388

63. Darlin L, Borgfeldt C, Forslund O, Hénic E, Hortlund M, Dillner J, et al. Comparison of use of vaginal HPV self-sampling and offering flexible appointments as strategies to reach long-term non-attending women in organized cervical screening. J Clin Virol (2013) 58(1):155-60. doi:10.1016/j.jcv.2013.06.029

64. Sancho-Garnier H, Tamalet C, Halfon P, Leandri FX, Le Retraite L, Djoufelkit $\mathrm{K}$, et al. HPV self-sampling or the Pap-smear: a randomized study among cervical screening nonattenders from lower socioeconomic groups in France. Int J Cancer (2013) 133(11):2681-7. doi:10.1002/ijc.28283

65. Wikström I, Lindell M, Sanner K, Wilander E. Self-sampling and HPV testing or ordinary Pap-smear in women not regularly attending screening: a randomised study. Br J Cancer (2011) 105(3):337-9. doi:10.1038/bjc.2011.236

66. Snijders PJ, Verhoef VM, Arbyn M, Ogilvie G, Minozzi S, Banzi R, et al. Highrisk HPV testing on self-sampled versus clinician-collected specimens: a review on the clinical accuracy and impact on population attendance in cervical cancer screening. Int J Cancer (2013) 132(10):2223-36. doi:10.1002/ijc.27790

67. Schmeink CE, Bekkers RL, Massuger LF, Melchers WJ. The potential role of self-sampling for high-risk human papillomavirus detection in cervical cancer screening. Rev Med Virol (2011) 21(3):139-53. doi:10.1002/rmv.686
68. Stewart DE, Gagliardi A, Johnston M, Howlett R, Barata P, Lewis N, et al. Selfcollected samples for testing of oncogenic human papillomavirus: a systematic review. J Obstet Gynaecol Can (2007) 29(10):817-28.

69. Waller J, McCaffery K, Forrest S, Szarewski A, Cadman L, Austin J, et al. Acceptability of unsupervised HPV self-sampling using written instructions. J Med Screen (2006) 13(4):208-13.

70. Zehbe I, Moeller H, Severini A, Weaver B, Escott N, Bell C, et al. Feasibility of self-sampling and human papillomavirus testing for cervical cancer screening in First Nation women from Northwest Ontario, Canada: a pilot study. BMJ Open (2011) 1(1):e000030. doi:10.1136/bmjopen-2010-000030

71. Castle PE, Rausa A, Walls T, Gravitt PE, Partridge EE, Olivo V, et al. Comparative community outreach to increase cervical cancer screening in the Mississippi Delta. Prev Med (2011) 52(6):452-5. doi:10.1016/j.ypmed.2011.03.018

72. Howard M, Lytwyn A, Lohfeld L, Redwood-Campbell L, Fowler N, Karwalajtys T. Barriers to acceptance of self-sampling for human papillomavirus across ethnolinguistic groups of women. Can J Public Health (2009) 100(5): 365-9.

73. Anhang R, Nelson JA, Telerant R, Chiasson MA, Wright TC Jr. Acceptability of self-collection of specimens for HPV DNA testing in an urban population. J Womens Health (Larchmt) (2005) 14(8):721-8. doi:10.1089/jwh.2005.14.721

74. Dzuba IG, Díaz EY, Allen B, Leonard YF, Lazcano Ponce EC, Shah KV, et al. The acceptability of self-collected samples for HPV testing vs. the pap test as alternatives in cervical cancer screening. J Womens Health Gend Based Med (2002) 11(3):265-75. doi:10.1089/152460902753668466

75. Forrest S, McCaffery K, Waller J, Desai M, Szarewski A, Cadman L, et al. Attitudes to self-sampling for HPV among Indian, Pakistani, African-Caribbean and White British women in Manchester, UK. J Med Screen (2004) 11(2):85-8.

76. Kitchener HC, Almonte M, Gilham C, Dowie R, Stoykova B, Sargent A, et al. ARTISTIC: a randomised trial of human papillomavirus (HPV) testing in primary cervical screening. Health Technol Assess (2009) 13(51):1-150,iii-iv. doi: $10.3310 /$ hta 13510

77. Bulkmans NW, Berkhof J, Rozendaal L, van Kemenade FJ, Boeke AJ, Bulk $\mathrm{S}$, et al. Human papillomavirus DNA testing for the detection of cervical intraepithelial neoplasia grade 3 and cancer: 5-year follow-up of a randomised controlled implementation trial. Lancet (2007) 370(9601):1764-72. doi:10.1016/S0140-6736(07)61450-0

78. Anhang R, Goodman A, Goldie SJ. HPV communication: review of existing research and recommendations for patient education. CA Cancer J Clin (2004) 54(5):248-59. doi:10.3322/canjclin.54.5.248

79. Maissi E, Marteau TM, Hankins M, Moss S, Legood R, Gray A. Psychological impact of human papillomavirus testing in women with borderline or mildly dyskaryotic cervical smear test results: cross sectional questionnaire study. BMJ (2004) 328(7451):1293. doi:10.1136/bmj.328.7451.1293

80. Maissi E, Marteau TM, Hankins M, Moss S, Legood R, Gray A. The psychological impact of human papillomavirus testing in women with borderline or mildly dyskaryotic cervical smear test results: 6-month follow-up. Br J Cancer (2005) 92(6):990-4. doi:10.1038/sj.bjc.6602411

81. Drolet M, Brisson M, Maunsell E, Franco EL, Coutlée F, Ferenczy A, et al. The psychosocial impact of an abnormal cervical smear result. Psychooncology (2012) 21(10):1071-81. doi:10.1002/pon.2003

82. McCaffery K, Waller J, Forrest S, Cadman L, Szarewski A, Wardle J. Testing positive for human papillomavirus in routine cervical screening: examination of psychosocial impact. BJOG (2004) 111(12):1437-43. doi:10.1111/j.1471-0528. 2004.00279.x Erratum in: BJOG (2004) 111(12):1489

83. McCaffery K, Waller J, Nazroo J, Wardle J. Social and psychological impact of HPV testing in cervical screening: a qualitative study. Sex Transm Infect (2006) 82(2):169-74. doi:10.1136/sti.2005.016436

84. McCaffery K, Irwig L. Australian women's needs and preferences for information about human papillomavirus in cervical screening. J Med Screen (2005) 12(3):134-41. doi:10.1258/0969141054855238

85. Anhang R, Wright TC Jr, Smock L, Goldie SJ. Women's desired information about human papillomavirus. Cancer (2004) 100(2):315-20. doi:10.1002/cncr. 20007

86. Kahn JA, Slap GB, Bernstein DI, Tissot AM, Kollar LM, Hillard PA, et al. Personal meaning of human papillomavirus and Pap test results in adolescent and young adult women. Health Psychol (2007) 26(2):192-200. doi:10.1037/02786133.26 .2 .192 
87. Goldsmith MR, Bankhead CR, Kehoe ST, Marsh G, Austoker J. Information and cervical screening: a qualitative study of women's awareness, understanding and information needs about HPV. J Med Screen (2007) 14(1):29-33. doi:10.1258/096914107780154459

88. McCree DH, Sharpe PA, Brandt HM, Robertson R. Preferences for sources of information about abnormal Pap tests and HPV in women tested for HPV. Prev Med (2006) 43(3):165-70. doi:10.1016/j.ypmed.2006.04.001

89. Perrin KK, Daley EM, Naoom SF, Packing-Ebuen JL, Rayko HL, McFarlane M, et al. Women's reactions to HPV diagnosis: insights from in-depth interviews. Women Health (2006) 43(2):93-110. doi:10.1300/J013v43n02_06

90. Rosen NO, Knäuper B, Pagé G, Di Dio P, Morrison E, Mayrand MH, et al. Brief research report: uncertainty-inducing and reassuring facts about HPV: a descriptive study of French Canadian women. Health Care Women Int (2009) 30(10):892-902. doi:10.1080/07399330903066434

91. Sharpe PA, Brandt HM, McCree DH. Knowledge and beliefs about abnormal pap test results and HPV among women with high-risk HPV: results from in-depth interviews. Women Health (2005) 42(2):107-33. doi:10.1300/ J013v42n02 07

92. Brotherton JM, Mullins RM. Will vaccinated women attend cervical screening? A population based survey of human papillomavirus vaccination and cervical screening among young women in Victoria, Australia. Cancer Epidemiol (2012) 36(3):298-302. doi:10.1016/j.canep.2011.11.005

93. Kulasingam SL, Pagliusi S, Myers E. Potential effects of decreased cervical cancer screening participation after HPV vaccination: an example from the U.S. Vaccine (2007) 25(48):8110-3. doi:10.1016/j.vaccine.2007.09.035

94. Bauch CT, Li M, Chapman G, Galvani AP. Adherence to cervical screening in the era of human papillomavirus vaccination: how low is too low? Lancet Infect Dis (2010) 10(2):133-7. doi:10.1016/S1473-3099(10)70004-9

95. Goldhaber-Fiebert JD, Stout NK, Ortendahl J, Kuntz KM, Goldie SJ, Salomon JA. Modeling human papillomavirus and cervical cancer in the United States for analyses of screening and vaccination. Popul Health Metr (2007) 5:11. doi:10.1186/1478-7954-5-11

96. Goldhaber-Fiebert JD, Stout NK, Salomon JA, Kuntz KM, Goldie SJ. Costeffectiveness of cervical cancer screening with human papillomavirus DNA testing and HPV-16,18 vaccination. J Natl Cancer Inst (2008) 100(5):308-320. doi:10.1093/jnci/djn019

97. Hilton S, Smith E. "I thought cancer was one of those random things. I didn't know cancer could be caught...": adolescent girls' understandings and experiences of the HPV programme in the UK. Vaccine (2011) 29(26):4409-15. doi:10.1016/j.vaccine.2011.03.101

98. Brankovic I, Verdonk P, Klinge I. Applying a gender lens on human papillomavirus infection: cervical cancer screening, HPV DNA testing, and HPV vaccination. Int J Equity Health (2013) 8(12):14. doi:10.1186/1475-9276-12-14

99. Mather T, McCaffery K, Juraskova I. Does HPV vaccination affect women's attitudes to cervical cancer screening and safe sexual behaviour? Vaccine (2012) 30(21):3196-201. doi:10.1016/j.vaccine.2012.02.081

100. Lefevere E, Hens N, Theeten H, van den Bosch K, Beutels P, De Smet F, et al. Like mother, like daughter? Mother's history of cervical cancer screening and daughter's human papillomavirus vaccine uptake in Flanders (Belgium). Vaccine (2011) 29(46):8390. doi:10.1016/j.vaccine.2011.08.039

101. Steens A, Wielders CC, Bogaards JA, Boshuizen HC, de Greeff SC, de Melker HE. Association between human papillomavirus vaccine uptake and cervical cancer screening in the Netherlands: implications for future impact on prevention. Int J Cancer (2013) 132(4):932-43. doi:10.1002/ijc.27671

102. Chao C, Slezak JM, Coleman KJ, Jacobsen SJ. Papanicolaou screening behavior in mothers and human papillomavirus vaccine uptake in adolescent girls. Am J Public Health (2009) 99(6):1137-42. doi:10.2105/AJPH.2008.147876

103. Mehta NR, Julian PJ, Meek JI, Sosa LE, Bilinski A, Hariri S, et al. Human papillomavirus vaccination history among women with precancerous cervical lesions: disparities and barriers. Obstet Gynecol (2012) 119(3):575-81. doi:10.1097/AOG.0b013e3182460d9f

104. PASSI. Progressi delle Aziende Sanitarie per la Salute in Italia. Rapporto Annuale. (2011). Available from: http://www.epicentro.iss.it/passi/rapporto2011/R2011 Indice.asp

105. Papilloomavirustautien torjuntatyöryhmä. Terveyden ja hyvinvoinnin laitoksen asettaman papillomavirustautien torjuntatyöryhmän selvitys [Finnish]. Terveyden ja hyvinvoinnin laitos (THL) (2011). Raportti 28/2011. 121 p.
106. Palència L, Espelt A, Rodríguez-Sanz M, Puigpinós R, Pons-Vigués M, Pasarín $\mathrm{MI}$, et al. Socio-economic inequalities in breast and cervical cancer screening practices in Europe: influence of the type of screening program. Int J Epidemiol (2010) 39(3):757-65. doi:10.1093/ije/dyq003

107. Sundhedsstyrelsen Center for Evaluering og MTV Voeskebaseretteknik og Udstrygningsteknik Anvendt til Screening for Livmoderhalskrafti Danmark: en Medicinsk Teknologivurdering. København: Center for Evaluering og Medicinsk Teknologivurdering (2005). Sundhedsstyrelsen Report No. 7(3).

108. Wikström I, Stenvall H, Wilander E. Attitudes to self-sampling of vaginal smear for human papilloma virus analysis among women not attending organized cytological screening. Acta Obstet Gynecol Scand (2007) 86(6):720-5. doi:10.1080/00016340701303747

109. Meissner HI, Tiro JA, Yabroff KR, Haggstrom DA, Coughlin SS. Too much of a good thing? Physician practices and patient willingness for less frequent pap test screening intervals. Med Care (2010) 48(3):249-59. doi:10.1097/MLR. 0b013e3181ca4015

110. ISTAT. Unità Struttura e Dinamica Sociale: Indagine Multiscopo: Stato di Salute e uso dei Servizisanitari Anno 2004-2005. Roma: ISTAT (2006).

111. Martin-Moreno JM, Anttila A, von Karsa L, Alfonso-Sanchez JL, Gorgojo L. Cancer screening and health system resilience: keys to protecting and bolstering preventive services during a financial crisis. Eur J Cancer (2012) 48(14):2212-8. doi:10.1016/j.ejca.2012.02.060

112. Sawaya GF. Rightsizing cervical cancer screening: comment on "Cervical cancer screening with both human papillomavirus and Papanicolaou testing vs Papanicolaou testing alone". Arch Intern Med (2010) 170(11):985-6. doi:10.1001/archinternmed.2010.133

113. Formoso G, Liberati A, Magrini N. Practice guidelines: useful and "participative" method? Survey of Italian physicians by professional setting. Arch Intern Med (2001) 161(16):2037-42. doi:10.1001/archinte.161.16.2037

114. Grimshaw JM, Thomas RE, MacLennan G, Fraser C, Ramsay CR, Vale L, et al. Effectiveness and efficiency of guideline dissemination and implementation strategies. Health Technol Assess (2004) 8(6):iii-iv, 1-72.

115. Lerman C, Miller SM, Scarborough R, Hanjani P, Smith D. Adverse psychologic consequences of positive cytologic cervical screening. Am J Obstet Gynecol (1991) 165(3):658-62. doi:10.1016/0002-9378(91)90304-A

116. Campion MJ, Brown JR, McCance DJ, Atia W, Edwards R, Cuzick J, et al. Psychosexual trauma of an abnormal cervical smear. Br J Obstet Gynaecol (1988) 95(2):175-81. doi:10.1111/j.1471-0528.1988.tb06848.x

117. Basen-Engquist K, Pasket ED, Buzaglo J, Miller SM, Schover L, Wenzel LB, et al. Cervical cancer. Cancer (2003) 98(9):2009-14. doi:10.1002/cncr.11681

118. Bell S, Porter M, Kitchener H, Fraser C, Fisher P, Mann E. Psychological response to cervical screening. Prev Med (1995) 24(6):610-6. doi:10.1006/ pmed.1995.1096

119. Franco EL, Cuzick J, Hildesheim A, de Sanjose S. Issues in planning cervical cancer screening in the era of HPV vaccination. Vaccine (2006) 24(Suppl 3):171-7. doi:10.1016/j.vaccine.2006.05.061

Conflict of Interest Statement: Paolo Giorgi Rossi is the principal investigator of a project sponsored by the Italian Ministry of Health and data owner. For this project, Paolo Giorgi Rossi is in contact with Roche Diagnostics, Hologic Gen-Probe, Qiagen, Abbott, for tests at reduced price or free of cost. All other authors have no conflicts of interest.

Received: 30 November 2013; paper pending published: 13 January 2014; accepted: 24 January 2014; published online: 10 February 2014.

Citation: Giorgi Rossi P, Baldacchini F and Ronco G (2014) The possible effects on socio-economic inequalities of introducing HPV testing as primary test in cervical cancer screening programs. Front. Oncol. 4:20. doi: 10.3389/fonc.2014.00020

This article was submitted to Cancer Epidemiology and Prevention, a section of the journal Frontiers in Oncology.

Copyright (c) 2014 Giorgi Rossi, Baldacchini and Ronco. This is an open-access article distributed under the terms of the Creative Commons Attribution License (CC BY). The use, distribution or reproduction in other forums is permitted, provided the original author(s) orlicensor are credited and that the original publication in this journal is cited, in accordance with accepted academic practice. No use, distribution or reproduction is permitted which does not comply with these terms. 